\title{
Purificación y caracterización de una lectina de Amaranthus hypochondriacus, un compuesto antiproliferativo
}

\section{Purification and Characterization of a lectin from Amaranthus hypochondriacus, an antiproliferative compound}

\author{
Mengoni, Antonieta (1,2), Quiroga, Alejandra Viviana (1,3), Añón, María Cristina (1)
}

(1) Centro de Investigación y Desarrollo en Criotecnología de Alimentos (CIDCA-CONICET-UNLP), La Plata, Buenos Aires, Argentina - (2) Comisión de Investigaciones Científicas (CIC-PBA), La Plata, Buenos Aires, Argentina - (3) Facultad de Ciencias Agrarias y Forestales. Universidad Nacional de La Plata, La Plata, Buenos Aires, Argentina.

RECIBIDO: 29/2/2016 - APROBADO: 23/6/2016

\begin{abstract}
Resumen
Los alimentos ejercen una influencia importante en el desarrollo de diversas enfermedades no transmisibles, entre las que es posible incluir el cáncer. Por otra parte, existe información que da cuenta de que algunos alimentos o algún componente alimentario pueden proteger contra el desarrollo de esta enfermedad. El objetivo de este trabajo fue purificar, caracterizar y analizar la potencial actividad antiproliferativa de una lectina proveniente de Amaranthus hypochondriacus $(\mathrm{AH})$.

Para ello se purificó parcialmente la lectina a partir de harina desgrasada de AH (LPP). Se encontró una proteína con una masa molecular aproximada de $65-70 \mathrm{kDa}$, compuesta por dos subunidades de aproximadamente $35 \mathrm{kDa}$ unidas por interacciones no covalentes, con actividad hemaglutinante característica de las lectinas. Se estudió la inhibición de la proliferación celular utilizando la línea celular tumoral CaCo2/TC7 mediante el ensayo del cristal violeta. Además de la lectina parcialmente purificada, se estudió el efecto antiproliferativo de los aislados de Amaranhus hypochondriacus y mantegazzianus, y una lectina comercial de Amaranthus caudatus. Todas las muestras ensayadas mostraron efectos citotóxicos en forma de dosis respuesta.
\end{abstract}

Palabras clave: Actividad antiproliferativa, lectina de Amaranthus hypochondriacus.

\begin{abstract}
Food exerts an important influence on the development of several chronic diseases, including cancer. On the other hand there is evidence indicating that some food components can protect against the development of this disease. The aim of this work was to purify, characterize and analyze the potential antiproliferative activity of a lectin from Amaranthus hypochondriacus.

Lectin was partially purified from defatted Amaranthus hipochondriacus flour. A protein with an approximate molecular mass of $65-70 \mathrm{kDa}$, composed of two subunits of about $35 \mathrm{kDa}$ held together by noncovalent interactions with hemagglutinating activity characteristic of lectins was found. Inhibition of cell proliferation was studied using the tumor cell line $\mathrm{CaCo} 2 / \mathrm{TC} 7$ by the crystal violet assay. In addition to the partially purified lectin, the antiproliferative effect of Amaranhus hypochondriacus and mantegazzianus isolates, and a commercial lectin from Amaranthus caudatus was studied. All samples tested showed cytotoxic effects in a dose dependent way.

Keywords: Antiproliferative activity, Amaranth hypochondriacus lectin.
\end{abstract}

\section{Introducción}

Las enfermedades no transmisibles (ENT) son en la actualidad la principal causa de mortalidad mundial. De acuerdo a los datos aportados por el Instituto Nacional del Cáncer (INC), de los 57 millones de defunciones que se produjeron en 2008 en todo el mundo, las dos terceras partes se debieron a ENT, principalmente enfermedades cardiovasculares, cáncer, diabetes y enfermedades pulmonares crónicas. El cáncer fue responsable de 7,6 millones de muertes.
En Argentina, las ENT causan más del 60\% del total de las defunciones que se producen anualmente en el país, $20 \%$ de las cuales corresponden a tumores. Argentina se encuentra dentro del rango de países con incidencia de cáncer media-alta (172,3-242,9 x 100000 habitantes), según las estimaciones realizadas por la Agencia Internacional de Investigación de Cáncer para el año 2012 (International Agency for Research on Cancer, IARC, Globocan, 2012). 
Un gran porcentaje de ENT son prevenibles y comparten los mismos factores de riesgo. Se estima que los cinco riesgos principales para la salud están relacionados con el comportamiento y la alimentación: índice alto de masa corporal, bajo consumo de frutas y hortalizas, inactividad física, consumo de tabaco e ingesta excesiva de alcohol. Estos factores causan el 30\% de las muertes por cáncer (Instituto Nacional del Cáncer, 2012).

A su vez, existe evidencia creciente de que algunos componentes de diferentes alimentos pueden proteger del desarrollo de esta enfermedad (péptidos, proteínas, metabolitos secundarios) (World Cancer Research Fund, 2007).

Dentro de los componentes bioactivos presentes en distintos alimentos se han encontrado algunos péptidos y proteínas que se utilizan como medicinas alternativas en el tratamiento del cáncer (Bhutia y Maiti, 2008; González de Mejia y Dia, 2010) entre los que pueden mencionarse a lunasina (Hernández-Ledesma, et al., 2009), el inhibidor de Bowman Birk (Kobayashi, 2013) y algunas lectinas provenientes de plantas (González de Mejía y Prisecaru, 2005; Lam y Ng, 2011; Liu, et al., 2010).

El amaranto, un cultivo precolombino de alto contenido proteico (12-17\% p/p), es considerado una importante fuente de compuestos bioactivos (Caselato-Sousa y Amaya Farfán, 2012; Rastogi y Shukla, 2013). Se han descripto péptidos bioactivos derivados de sus proteínas con diferentes actividades biológicas, entre ellas, antimicrobiana, antioxidante, antitrombótica y antihipertensiva (Lipkin, et al., 2005; Fritz, et al, 2011; Orsini Delgado, et al., 2011; Caselato-Sousa y Amaya Farfán, 2012; Quiroga, et al., 2012; Tironi y Añón, 2014; García Fillería y Tironi, 2015; Orsini Delgado, et al.; 2015; Sabbione, et al., 2015).

Silva-Sánchez et al. (2008) encontraron un péptido de $\approx 20$ $\mathrm{kDa}$ en la fracción glutelina del Amaranthus hypochondriacus similar a lunasina con propiedades antitumorales potenciales. Barrio y Añón (2010) informaron actividad antiproliferativa en el aislado proteico de Amaranthus mantegazzianus y su mecanismo de acción en diferentes líneas tumorales y no tumorales. Quiroga et al. (2015) estudiaron la actividad antiproliferativa de las diferentes fracciones proteicas que componen el aislado y trataron de identificar la/las proteína/s y/o péptidos responsables de la actividad utilizando la línea celular UMR106 derivada de osteosarcoma de rata. En base a la evidencia experimental encontrada propusieron a la lectina de Amaranthus mantegazzianus como la responsable de la actividad antiproliferativa.

Si bien existen evidencias de la actividad antiproliferativa asociada a lectina de amaranto obtenida de distintas variedades de este cultivo (Yu, et al., 2001; Kaur, et al., 2006; Quiroga, et al., 2015), es necesario profundizar el conocimiento en cuanto a la purificación, las características estructurales y el estudio de sus posibles mecanismos de acción para poder aplicarla en el desarrollo de un alimento funcional. De lo que antecede, el objetivo de este trabajo fue obtener, purificar y caracterizar lectina de Amaranthus hypochondriacus y determinar la actividad antiproliferativa de la lectina parcialmente purificada utilizando la línea celular tumoral Caco2/TC7.

\section{Materiales y Métodos}

\section{Obtención de las muestras}

Las semillas utilizadas en los ensayos realizados pertenecen a la especie Amaranthus hypochondriacus, recibidas de INDEAR (Instituto de Agrobiotecnología Rosario), Rosario, Santa Fe, Argentina. Se obtuvo la harina a partir de las semillas utilizando un molino UDY Cyclone Sample Mill, de 0,5 mm de malla. La harina obtenida fue desgrasada con n-hexano con una relación $10 \% \mathrm{p} / \mathrm{v}$ durante $5 \mathrm{~h}$ con agitación a temperatura ambiente y luego se mantuvo $20 \mathrm{~h}$ más en contacto con el solvente, en reposo. Posteriormente se filtró con vacío y se dejó secar al aire para eliminar los restos de solvente durante 24 hs antes de ser utilizada.

\section{Lectina de Amaranto hypochondriacus. Obtención y purificación}

La lectina parcialmente purificada se preparó según el protocolo descrito por Rinderle et al. (1989). A partir de la harina desgrasada se extrajo con buffer fosfato (PBS: 0,011 mol/L $\left.\mathrm{KH}_{2} \mathrm{PO}_{4}, 0,026 \mathrm{~mol} / \mathrm{L} \mathrm{Na}_{2} \mathrm{HPO}_{4}, 0,115 \mathrm{~mol} / \mathrm{L} \mathrm{NaCl}, \mathrm{pH} 7,4\right)$ durante $1 \mathrm{~h}$. El extracto proteico se precipitó con una concentración de $\left(\mathrm{NH}_{4}\right)_{2} \mathrm{SO}_{4}$ entre $1,2 \mathrm{~mol} / \mathrm{L}-3,2 \mathrm{~mol} / \mathrm{L}$, a una temperatura de $4{ }^{\circ} \mathrm{C}$.

El precipitado obtenido se resuspendió en una solución de tris(hidroximetil)aminometano (Tris), 0,020 mol/L, $\mathrm{pH}$ 8,1 y se dializó exhaustivamente contra el mismo buffer (este extracto se denominó extracto crudo EC). Luego de la diálisis la muestra se purificó mediante cromatografía de intercambio aniónico utilizando una columna MonoQ 5/50 GL (GE-Healthcare, Uppsala, Sweden) equilibrada con 0,020 $\mathrm{mol} / \mathrm{L}$ Tris, $\mathrm{pH} 8,10$. Se sembraron $2 \mathrm{ml}$ del extracto crudo en cada corrida. Se utilizó un flujo de $0,5 \mathrm{ml} / \mathrm{min}$. La muestra no retenida por la columna (fracción A) se eluyó con 10 volúmenes de columna del solvente de baja fuerza iónica (fase móvil A: buffer Tris $0,02 \mathrm{~mol} / \mathrm{L}, \mathrm{pH} 8,1$ ). La fracción retenida (fracción B) se eluyó con buffer de alta fuerza iónica (fase móvil B: buffer Tris $0,02 \mathrm{~mol} / \mathrm{L}, \mathrm{pH} 8,1, \mathrm{NaCl} 1 \mathrm{M}$ ) utilizando un gradiente lineal de solvente entre $0-100 \%$ fase móvil $\mathrm{B}$ desarrollado en 5 volúmenes de columna. Ambas fracciones se dializaron contra agua y se liofilizaron.

\section{Aislado de Amaranto hypochondriacus y Amaranto mantegazzianus}

Los aislados proteicos se prepararon según lo descrito por Martínezy Añón (1996). Brevemente, las proteínas fueron extraídas a partir de harina desgrasada a $\mathrm{pH} 9$ y precipitadas a $\mathrm{pH}$. El precipitado fue resuspendido en agua, neutralizado y liofilizado.

\section{Lectina comercial}

Se utilizó como control una lectina comercial de Amaranthus caudatus adquirida en Vector laboratories (Burlingame, CA, USA).

\section{Caracterización de lectina parcialmente purificada}

\section{Electroforesis}

Se utilizó un equipo Bio Rad miniprotean II (Bio-Rad Hercules, California, USA), siguiendo el protocolo descrito por Laemmli (1970). Se utilizaron geles de concentración constante de acrilamida $12 \% \mathrm{p} / \mathrm{v}$ para el gel separador y $4 \% \mathrm{p} / \mathrm{v}$ para el gel apilador. Se utilizaron marcadores de peso molecular en el rango (14,1-97 kDa) (GE-Healthcare, Upsala, Suecia). Los geles fueron fijados y teñidos con Coomasie brilliant Blue R-250 al 0,192\% p/v en agua/metanol/ácido acético (10:10:4) 
durante $12 \mathrm{~h}$, en agitación. La decoloración se realizó con una solución de etanol 25\% p/v y ácido acético $10 \%$ p/v a temperatura ambiente.

Las muestras se prepararon disolviendo la proteína en buffer de muestra (hidroximetil aminometano-HCl (Tris$\mathrm{HCl}) 0,185 \mathrm{M}(\mathrm{pH} 8,8)$, glicerol $12,5 \% \mathrm{v} / \mathrm{v}$, dodecil sulfato de sodio (SDS) 2,0\% p/v, y azul de bromofenol 0,05\% p/v). En el caso de muestras liofilizadas las muestras se prepararon a una concentración proteica aproximada de $10 \mathrm{mg} / \mathrm{ml}$. Las muestras en solución se prepararon mezclando 3 volúmenes de muestra con 1 volumen de buffer de muestra. Para la electroforesis en condiciones reductoras se agregó a la muestra 2 -mercaptoetanol en una concentración de $5 \%$ v/v y luego se calentó a ebullición durante 1 min en baño María. Todas las muestras se centrifugaron antes de sembrar en el gel durante $10 \mathrm{~min}$ a $14000 \mathrm{~g}$ a $25^{\circ} \mathrm{C}$. Los sobrenadantes se sembraron en el gel en cierto volumen para tener entre 20-60 $\mu \mathrm{g}$ de proteína por calle.

Para la corrida de los geles se utilizó un voltaje de $200 \mathrm{~V}$ y una corriente de $30 \mathrm{~A}$ por placa, usando como buffer de

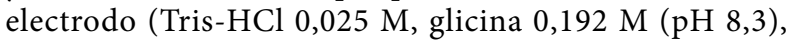
SDS $0,1 \% \mathrm{p} / \mathrm{v})$.

\section{Cromatografía de exclusión molecular}

Se utilizó una columna Superosa 6HR 10/300 GL (GE Healthcare), cuyo rango de separación es de $5000 \mathrm{Da}$ a 5000000 Da. Las muestras fueron disueltas en $0,2 \mathrm{ml}$ de buffer Tris $20 \mathrm{mM}, \mathrm{NaCl} 0,1 \mathrm{M}, \mathrm{pH}=8$, y fueron eluídas con el mismo buffer con un flujo de $0,2 \mathrm{ml} / \mathrm{min}$. Se colectaron fracciones cada $0,5 \mathrm{ml}$ y se registró el perfil de elución midiendo la absorbancia a $214 \mathrm{~nm}$. La columna fue calibrada con un kit de calibración HMW gel filtration calibration kit (Ge Healthcare) que contiene las siguientes proteínas: Tiroglobulina (669kDa, $\mathrm{Ve}=12,2 \mathrm{ml})$, Aldolasa $(158 \mathrm{kDa}, \mathrm{Ve}=15,7 \mathrm{ml})$, Albúmina bovina $(67 \mathrm{kDa}, \mathrm{Ve}=16,4 \mathrm{ml})$, ovoalbúmina (43 $\mathrm{kDa}, \mathrm{Ve}=17,1 \mathrm{ml})$, ribonucleasa $\mathrm{A}(13,7 \mathrm{kDa}, \mathrm{Ve}=18,8 \mathrm{ml})$. Se utilizó azul dextrano para determinar el volumen muerto de la columna ( $\mathrm{V} 0=7,2 \mathrm{ml})$.

\section{Ensayo de hemaglutinación}

A partir de glóbulos rojos obtenidos de sangre humana de cualquier tipo y factor se preparó una suspensión al 4\% v/v con solución fisiológica.

Con las muestras obtenidas en la cromatografía de intercambio iónico, dializadas y liofilizadas (fracción A y fracción B) se prepararon suspensiones de $5 \mathrm{mg}$ liofilizado $/ \mathrm{ml}$ en buffer PBS. A partir de ellas se realizaron diluciones utilizando como disolvente solución fisiológica. Para el extracto crudo (muestra líquida) se realizaron diluciones utilizando solución fisiológica.

Se utilizó como control positivo de hemaglutinación una lectina comercial de Amaranthus caudatus. Se diluyó con solución fisiológica hasta una concentración de $0,04 \mathrm{mg} / \mathrm{ml}$ y se ensayaron las siguientes concentraciones: $20 \mu \mathrm{g} / \mathrm{ml}, 10$ $\mu \mathrm{g} / \mathrm{ml}, 5 \mu \mathrm{g} / \mathrm{ml}$ y $2 \mu \mathrm{g} / \mathrm{ml}$.

Para llevar a cabo el ensayo, se colocaron $50 \mu \mathrm{L}$ de la suspensión de glóbulos rojos y $50 \mu \mathrm{L}$ de las diluciones preparadas en cada pocillo de fondo curvo de una placa ELISA, realizando triplicados para cada concentración. Se agregó un control negativo en el cual se colocaron $50 \mu \mathrm{L}$ de la suspensión de eritrocitos y $50 \mu \mathrm{L}$ de solución fisiológica. La hemagluti- nación se observó luego de 1 h de incubación a temperatura ambiente (Rinderle, et al., 1989).

\section{Determinación \\ de la actividad antiproliferativa}

\section{Cultivo de las células Caco-2/TC7}

Las células provenientes de epitelio colorrectal de adenocarcinoma humano, Caco- $2 / \mathrm{TC} 7$, fueron cultivadas en frascos de plástico de $75 \mathrm{~cm}^{3}$ a $37^{\circ} \mathrm{C}$ en atmósfera humidificada con $5 \%$ de $\mathrm{CO}_{2}$ en medio de cultivo Dulbelcco's Modified Eagle Medium (DMEM, Gibco BRL, Argentina), suplementado con $10 \%$ de suero fetal bovino (SFB), penicilina (100 UI/ml) y estreptomicina $(100 \mu \mathrm{g} / \mathrm{ml})$. Las células se incubaron hasta su crecimiento en confluencia, de tres a cinco días. Se trataron con tripsina utilizando tripsina-EDTA en buffer fosfato (PBS) y se resuspendieron en DMEM suplementado con SFB. Se colocaron $2,4 \times 10^{4}$ células por pocillo en placas de 48 pocillos, se cultivaron hasta alcanzar confluencia utilizando DMEM como medio.

\section{Ensayo de proliferación celular}

La actividad antiproliferativa se midió mediante la evaluación del desprendimiento celular por tinción con cristal violeta, según Okajima et al. (1992), con algunas modificaciones.

Se ensayó la actividad de las siguientes muestras: aislado de Amaranthus hypochondriacus, aislado de Amaranthus mantegazzianus, lectina comercial y lectina parcialmente purificada. Para la preparación de los stocks de las muestras a ensayar se solubilizaron las muestras en DMEM y se agitaron durante $90 \mathrm{~min}$ en Thermomixer comfort (Eppendorf) a $650 \mathrm{rpm}$ y $35^{\circ} \mathrm{C}$, pasándolas por vórtex cada $10 \mathrm{~min}$. Se centrifugaron las muestras a $20000 \mathrm{~g}$ durante $20 \mathrm{~min}$ y se utilizó el sobrenadante. Las muestras stock se filtraron con un filtro de $0,22 \mu \mathrm{m}$ de tamaño de poro y se realizaron diluciones con el DMEM y DMEM + SFB (10\%) para tener una concentración final constante de SFB de $1 \%$ en todas las diluciones ensayadas.

En la placa con el cultivo celular se colocaron $0,5 \mathrm{ml}$ de DMEM + FBS (1\%) en las fosas utilizadas como control negativo de actividad. Al resto de las fosas se le agregó $0,5 \mathrm{ml}$ de las diluciones de las muestras ensayadas. Se incubaron $24 \mathrm{~h}$ a $37^{\circ} \mathrm{C}$ y se realizaron lavados con PBS. Se incorporó glutaraldehído al 5\% v/v en PBS para fijar las células y se agregaron $0,5 \mathrm{ml}$ de colorante (cristal violeta $5 \mathrm{mg} / \mathrm{ml}$ en agua:metanol $75: 25 \mathrm{v} / \mathrm{v}$ ) a cada fosa, dejándolo $10 \mathrm{~min}$ en contacto con las células. Se lavaron las fosas con PBS y etanol, hasta ver que en los lavados no se extraía más colorante. Se agregaron 0,5 $\mu \mathrm{L}$ de buffer de extracción $(0,1 \mathrm{M}$ glicina/ $\mathrm{HCl} \mathrm{pH}=3,30 \%$ v/v de metanol) en cada fosa y se dejó en placa agitadora durante $1 \mathrm{~h}$. Luego se tomaron $0,2 \mathrm{ml}$ de cada fosa, y se midió absorbancia a $590 \mathrm{~nm}$.

\section{Análisis estadístico de los resultados}

Los resultados fueron analizados estadísticamente empleando el programa InfoStat. Se efectuaron análisis de varianza (ANAVA) y la comparación de medias se realizó con el test de la menor diferencia significativa (LSD). Todos los ensayos descriptos anteriormente fueron realizados por lo menos por triplicado, salvo en aquellos casos donde se indicó lo contrario. 


\section{Resultados y Discusión}

\section{Obtención y purificación de lectina de Amaranthus hypochondriacus}

La lectina de A. hypochondriacus fue aislada y purificada siguiendo el protocolo descripto para lectina de A. caudatus por Rinderle et al. (1989). Luego de la extracción con PBS y la precipitación con sulfato de amonio, se purificó por medio de una cromatografía de intercambio iónico.

El extracto crudo se separa en dos fracciones (Fracción A y Fracción B) luego de pasarlo por la columna de intercambio iónico. La Fracción A no queda retenida en la columna y eluye con buffer de baja fuerza iónica, mientras que la Fracción B eluye con el buffer de alta fuerza iónica. En la Figura 1 se muestra la separación obtenida en el intercambio iónico.

Para comprobar la presencia de lectina tanto en el extracto crudo como en las fracciones A y B se realizaron ensayos de hemaglutinación. Esta proteína tiene la capacidad de aglutinar los glóbulos rojos, por lo que una actividad positiva indica que la muestra analizada contiene lectina. Como control positivo de la hemaglutinación se utilizó una lectina comercial de Amaranthus caudatus. Como control negativo se utilizó solución fisiológica. Los resultados se muestran en la Figura 2.

Es posible observar la presencia de lectina tanto en el extracto crudo como en la Fracción A obtenida luego del intercambio iónico, mientras que no se evidencia la presencia de lectina en la Fracción B, al menos en las concentraciones

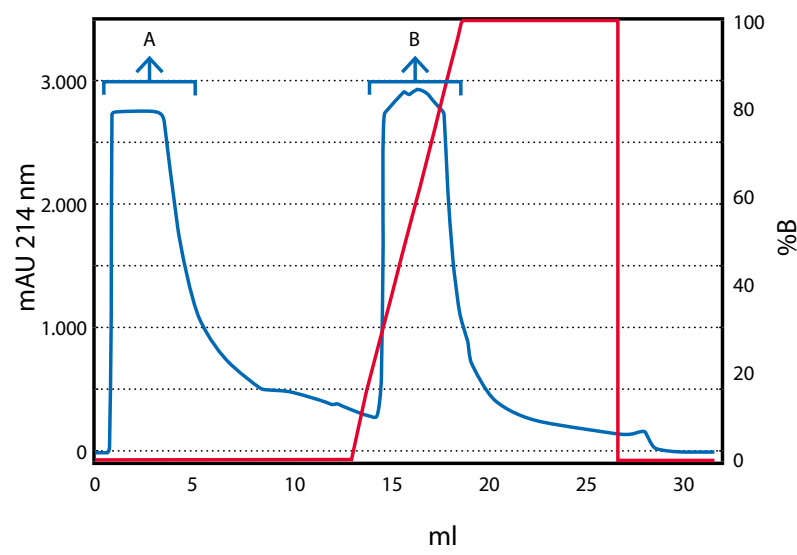

Figura 1. Cromatografía de intercambio aniónico del extracto crudo (Columna MonoQ 5/50 GL). Fracción A: fracción no retenida. Fracción B: fracción retenida que eluye con el gradiente. En línea roja se indica el gradiente salino.

ensayadas. Este resultado es acorde con lo informado por otros autores para lectinas extraídas de distintas especies de amaranto (Rinderle, et al., 1989; Singh, et al., 1993).

Tanto para la lectina comercial como para la fracción A se observa un efecto dosis respuesta, ya que al aumentar la concentración de proteína aumenta la hemaglutinación observada.

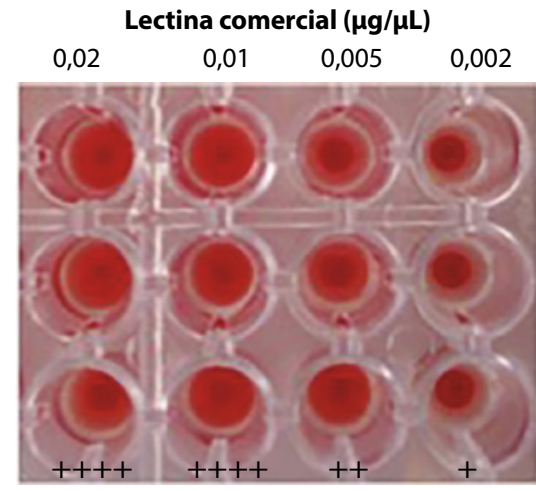

\section{Control negativo}
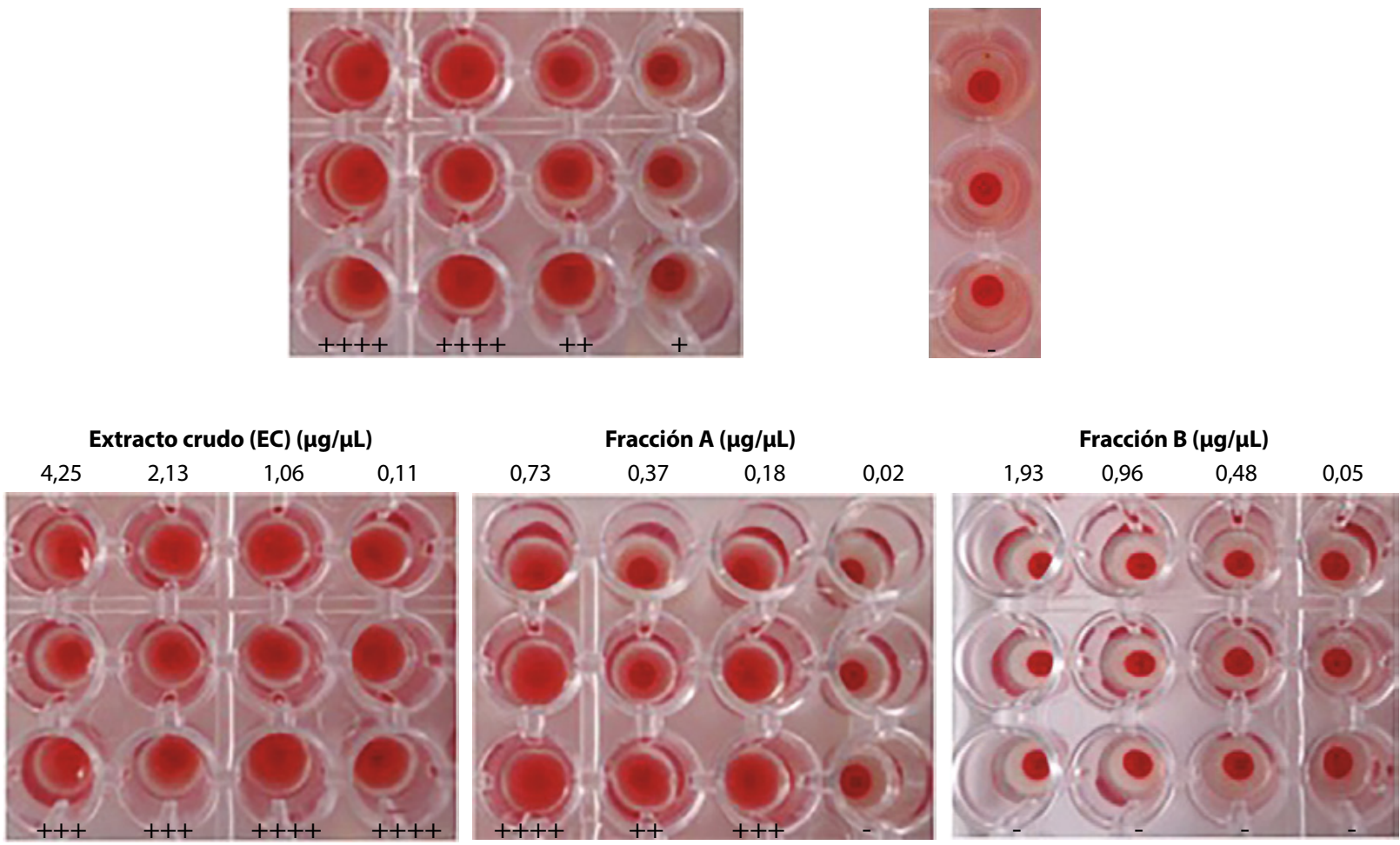

Figura 2. Ensayo de hemaglutinación. En la parte superior de las imágenes se indican las concentraciones ensayadas en $\mu \mathrm{g} / \mu \mathrm{l}$. En la parte inferior se indica cualitativamente el grado de hemaglutinación (++++ para el de mayor actividad y - para el que no posee actividad). La concentración de proteínas soluble se determinó utilizando el método de Lowry. 
En el extracto crudo no se observa un comportamiento dosis-respuesta, sino una mayor actividad hemaglutinante a medida que la dilución aumenta. En esta muestra aún se encuentran presentes muchos compuestos de distinta naturaleza, lo que podría dar lugar a la presencia de algún interferente de hemaglutinación que, al diluirse, permitiría que la lectina actúe más y se exprese una mayor actividad hemaglutinante.

En base a los resultados obtenidos se puede expresar que la purificación por medio de la columna de intercambio aniónico resultó efectiva para eliminar parcialmente las impurezas que acompañaban a la lectina en el extracto crudo.

El progreso de la purificación de lectina se siguió también mediante electroforesis de las fracciones obtenidas. La Figura $3 \mathrm{~A}$ presenta el perfil electroforético en condiciones no reductoras. Allí se puede ver la banda de lectina tanto en la muestra de lectina comercial (LC, aproximadamente 30 $\mathrm{kDa}$ ), como en el extracto crudo (EC). La Figura 3B muestra el perfil electroforético en condiciones reductoras. En estas condiciones se observa que aumenta la intensidad de las bandas y mejoran en cuanto a su definición. La banda de lectina (de aproximadamente $30 \mathrm{kDa}$, señalada con una punta de flecha) aparece en la Fracción A y en menor medida en la Fracción B. De acuerdo a los datos informados por distintos autores, la lectina de amaranto es un homodímero formado por dos polipéptidos de entre 30 y $35 \mathrm{kDa}$ unidos por interacciones no covalentes (Koeppe y Rupnow, 1988; Zenteno y Ochoa, 1988; Rinderle, et al., 1989; Rinderle, et al., 1990; Singh, et al., 1993; Singh, et al., 1994; Transue, et al., 1997). Sin embargo, en su secuencia contiene cisteínas que en presencia de un agente desnaturalizante y a $\mathrm{pH}$ alcalino en condiciones no reductoras podrían formar puentes disulfuro con otras cisteínas cercanas de otras moléculas de lectina o bien con cisteínas de polipéptidos de otras especies proteicas que se encuentren impurificando esta fracción, lo cual explicaría la variación en la intensidad de las bandas.
De acuerdo a los resultados obtenidos, se puede afirmar que la lectina eluye principalmente en la Fracción A obtenida en la cromatografía de intercambio iónico. Asimismo, es posible concluir que el paso de purificación mediante cromatografía de intercambio aniónico fue efectivo, eliminando parte de las proteínas no deseadas que impurificaban la lectina.

\section{Caracterización de lectina parcialmente purificada (LPP)}

Se analizó el perfil cromatográfico de la fracción LPP mediante cromatografía de exclusión molecular; los resultados se presentan en las Figuras 4A y 4B. Se comparó el perfil cromatográfico de LPP con el de lectina comercial (LC) de Amaranthus caudatus.

El perfil cromatográfico de lectina comercial mostró un pico principal que se corresponde con especies de aproximadamente $59 \mathrm{kDa}$ y dos picos de menor importancia de aproximadamente 7,6 y 2,7 kDa, respectivamente. La fracción LPP se separó en dos picos, uno de aproximadamente 67 $\mathrm{kDa}$ y el otro, más importante, de 11,5 kDa. Estos resultados se corresponden con los encontrados en bibliografía para la lectina de amaranto extraída de diferentes especies (Koeppe y Rupnow, 1988; Zenteno y Ochoa, 1988; Singh, et al., 1993; Singh, et al., 1994; Rinderle, et al., 1989; Rinderle, et al., 1990). De acuerdo a lo observado en el cromatograma correspondiente a LPP, podemos decir que en esta fracción aún hay especies diferentes a lectina contaminando la muestra. Estos contaminantes podrían ser de naturaleza proteica o no proteica, ya que para seguir la separación cromatográfica se midió la absorbancia a $214 \mathrm{~nm}$, y a esta longitud de onda pueden absorber varios compuestos de distinta naturaleza.

El eluato obtenido se recolectó en fracciones (1-7) (Figura $4 \mathrm{~B})$ que fueron analizadas por SDS-PAGE. El gel resultante se muestra en la Figura 4C. Se puede observar cómo la banda

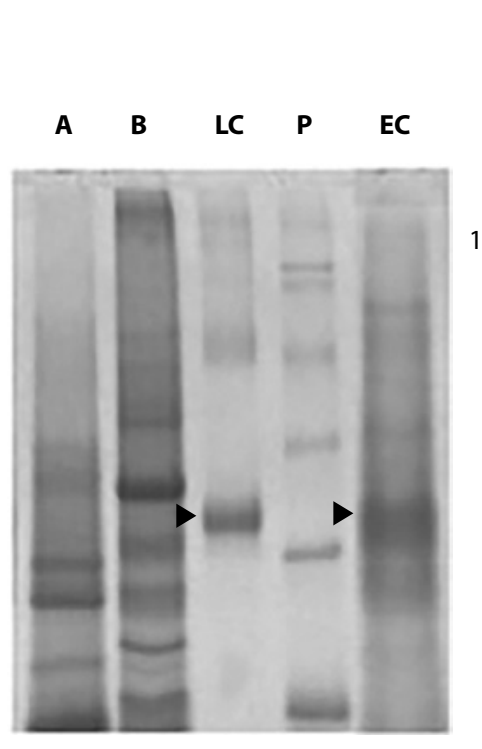

B.

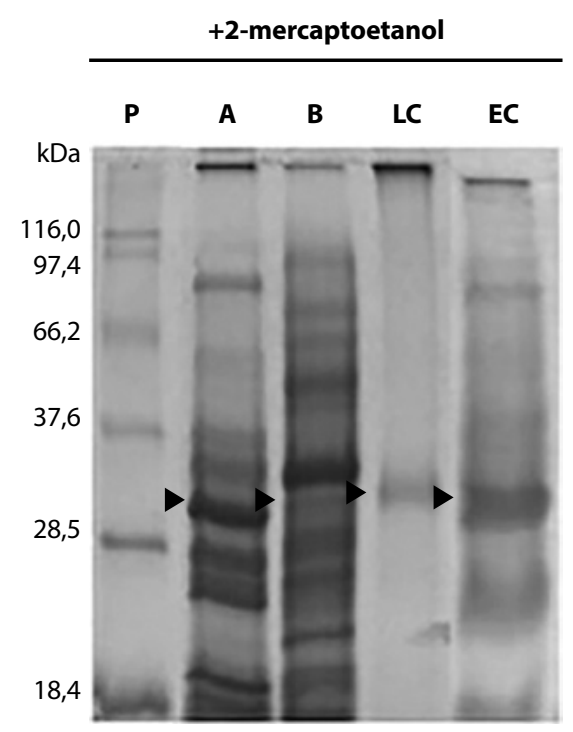

Figura 3. SDS-PAGE A) Sin 2-mercaptoetanol. B) Con 2-mercaptoetanol. P: patrón de bajo peso molecular; EC: extracto crudo; LC: lectina comercial; A: fracción A liofilizada; B: fracción B liofilizada. Las puntas de flechas indican la banda correspondiente a lectina. 

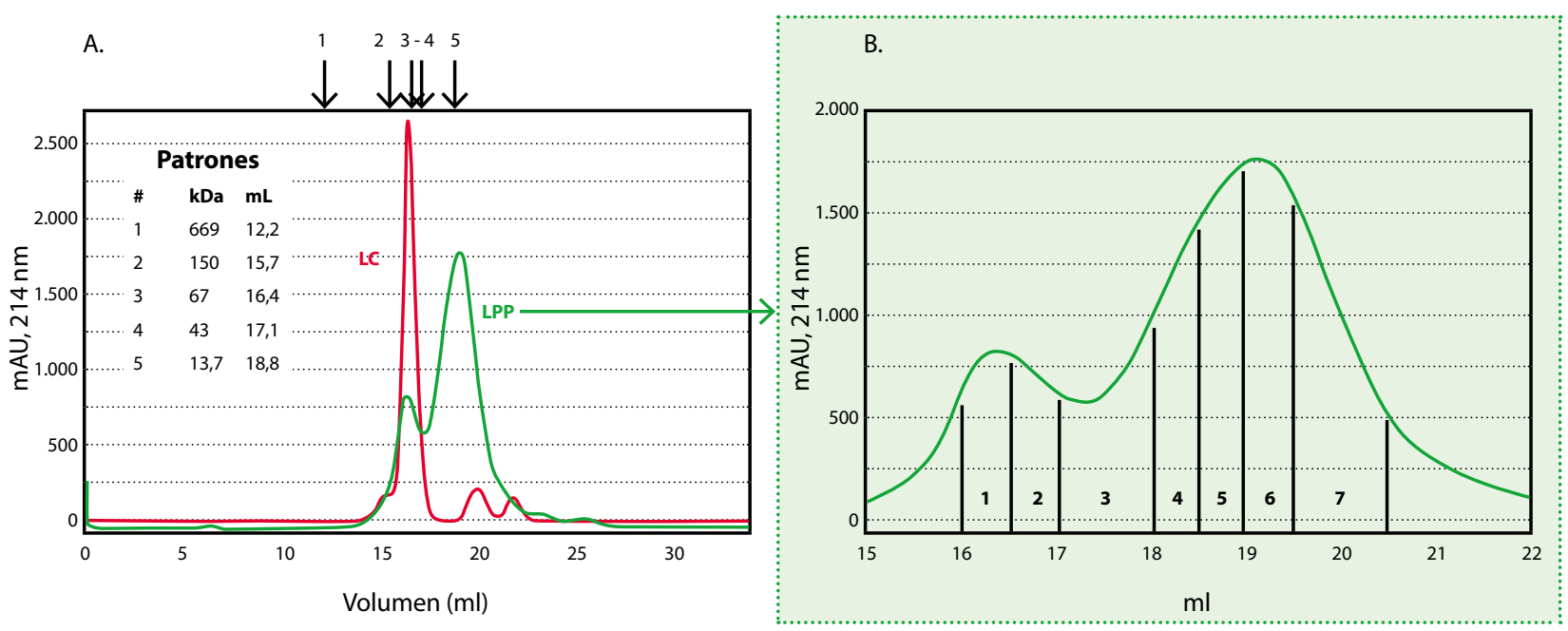

C.

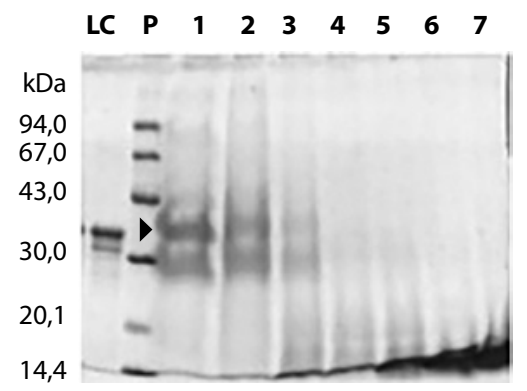

Figura 4. A. Cromatografía de exclusión molecular (Superosa 6HR 10/300 GL): LC: lectina comercial, LPP: lectina parcialmente purificada. Las flechas indican el volumen de elución (Ve, $\mathrm{ml})$ de los patrones de peso molecular: 1 Tiroglobulina $(669 \mathrm{kDa}, \mathrm{Ve}=12,2 \mathrm{ml}), 2$ Aldolasa $(158 \mathrm{kDa}, \mathrm{Ve}=15,7 \mathrm{ml}), 3$ Albúmnia bovina $(67 \mathrm{kDa}, \mathrm{Ve}=16,4 \mathrm{ml}), 4$ ovoalbúmina ( $43 \mathrm{kDa}, \mathrm{Ve}=17,1 \mathrm{ml}), 5$ ribonucleasa $(13,7 \mathrm{kDa}, \mathrm{Ve}=18,8 \mathrm{ml})$. B. Fracciones colectadas para LPP. C. SDS-PAGE de las fracciones colectadas. LC: lectina comercial; P: patrón de peso molecular, las masas de los patrones se indican a la izquierda de la figura.

correspondiente a lectina (señalada con una punta de flecha) va desapareciendo a medida que los volúmenes de elución aumentan. De acuerdo a estos resultados, se puede concluir que la lectina extraída de Amaranthus hypochondriacus es un dímero de masa aproximada $67 \mathrm{kDa}$ formado por dos subunidades de aproximadamente $35 \mathrm{kDa}$, similar a la lectina comercial proveniente de Amaranthus caudatus. El segundo pico $(11,5 \mathrm{kDa})$ presente en el perfil de LPP está compuesto por especies proteicas de baja masa molecular (señaladas con un círculo), aunque, como ya fue mencionado, pueden haber otras moléculas de origen no proteico que no son detectadas por esta técnica.

\section{Determinación de actividad antiproliferativa}

\section{Tinción con cristal violeta}

Este ensayo permite evidenciar la actividad antiproliferativa de distintos compuestos sobre diferentes líneas celulares. En este trabajo las muestras ensayadas fueron: aislado de Amaranthus mantegazzianus y de Amaranthus hypochondriacus, lectina comercial, lectina parcialmente purificada (LPP). Se utilizó la línea celular derivada de epitelio colorrectal de adenocarcinoma humano, Caco-2/TC7. En la Figura 5 se muestra la actividad antiproliferativa, medida como porcentaje de crecimiento celular, en función de la concentración proteica $(\mathrm{mg} / \mathrm{ml})$ para las distintas muestras analizadas. Una disminución en el crecimiento celular refleja un aumento de actividad antiproliferativa. En la Tabla 1 se comparan los valores de $\mathrm{IC}_{50}$ obtenidos para las muestras en estudio.

Se puede observar que todas las muestras presentan un comportamiento dosis respuesta.

Tanto el aislado de Amaranthus mantegazzianus (Figura 5A) como el aislado de Amaranthus hypochondriacus (Figura 5B) presentan una actividad antiproliferativa significativa, que resulta mayor para el primer caso. Mientras que para el aislado de Amaranthus mantegazzianus el $\mathrm{IC}_{50}$ es de 0,32 \pm $0,03 \mathrm{mg} / \mathrm{ml}$, para el aislado de Amaranthus hypochondriacus su $\mathrm{IC}_{50}$ es de $0,77 \pm 0,09 \mathrm{mg} / \mathrm{ml}$.

La lectina comercial (Figura 5C) también presentó actividad antiproliferativa, llegando a aproximadamente un $40 \%$ de inhibición del crecimiento celular a los $0,25 \mathrm{mg} / \mathrm{ml}$ de concentración proteica. Esto indica que su $\mathrm{IC}_{50}$ es mayor que $0,25 \mathrm{mg} / \mathrm{ml}$.

Para la lectina parcialmente purificada (LPP, Figura 5D), la actividad no es tan marcada como para los casos anteriores y la inhibición se da de una manera más gradual, llegando a un $20 \%$ 
para una concentración de $3,18 \mathrm{mg} / \mathrm{ml}$, por lo que no se pudo determinar un valor de $\mathrm{IC}_{50}$. Sin embargo, se puede afirmar que este valor será superior a $3,18 \mathrm{mg} / \mathrm{ml}$. La diferencia entre el comportamiento encontrado para el aislado y lectina parcialmente purificada de Amaranthus hypochondriacus podría explicarse considerando que en el aislado existen otros compuestos que podrían tener efecto antiproliferativo y de este modo ejercer un efecto sinérgico sobre las células. Por otra parte, no es posible descartar que entre los componentes que aún se encuentran impurificando la lectina exista algún compuesto proproliferativo que reduzca la acción de lectina sobre las células.

En un trabajo anterior (Quiroga, et al., 2015) se encontró que la lectina extraída de Amaranthus mantegazzianus tenía una actividad antiprolifertiva equivalente a la encontrada para lectina comercial cuando se utilizó una línea celular de osteosarcoma de rata (UMR106). Unido a los resultados encontrados en este trabajo, donde el aislado de A. mantegazzianus es mucho más activo que el de $A$. hypochondriacus para la línea celular derivada de epitelio colorrectal de adenocarcinoma humano (Caco-2/TC7), se puede sugerir que las lectinas extraídas de estas variedades no serían equivalentes en cuanto a su capacidad antiproliferativa.

\section{A. Aislado Amaranthus mantegazzianus}

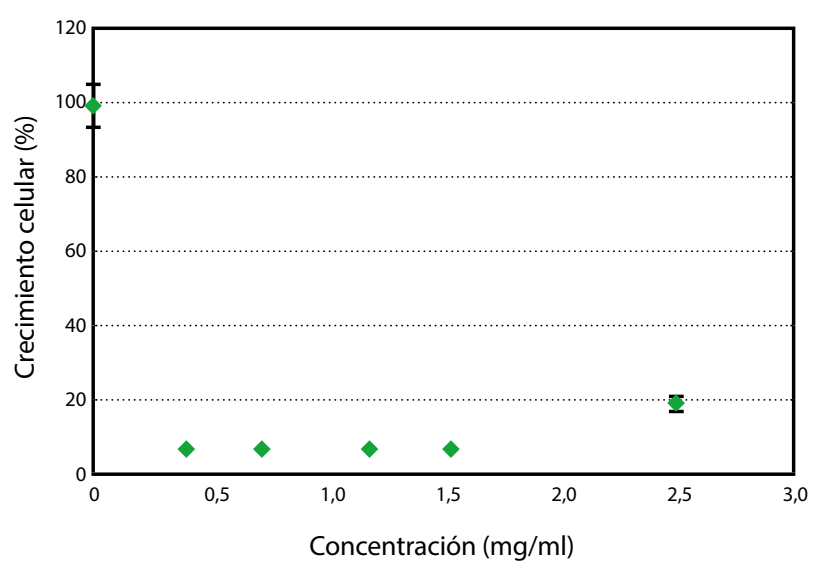

C. Lectina comercial

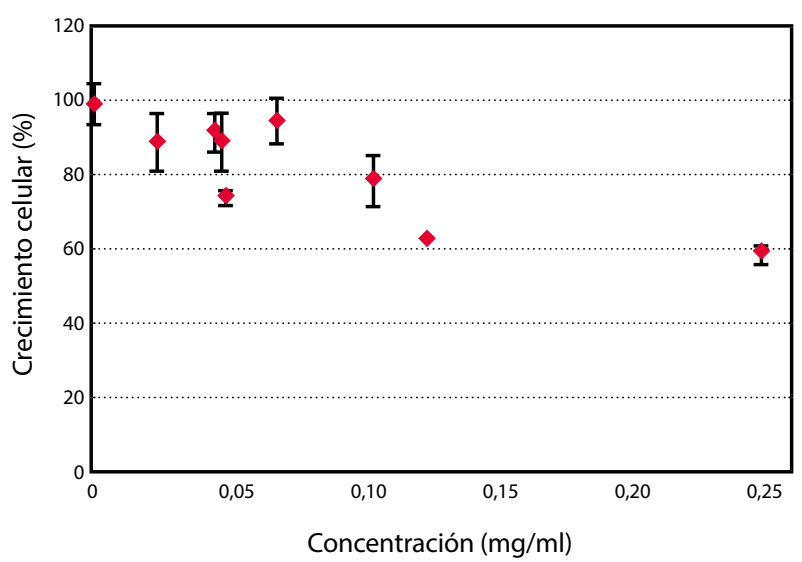

Ensayos preliminares que evalúan el posible mecanismo de acción de LPP y los aislados de Amaranthus hypochondriacus y mantegazzianus (resultados no mostrados) sugieren que esta proteína actuaría a nivel mitocondrial y lisosomal sobre las células tumorales, provocando efectos citotóxicos que conducirían a la muerte celular.

\begin{tabular}{|c|c|}
\hline Muestras & $\mathrm{IC}_{50}(\mathrm{mg} / \mathrm{ml})$ \\
\hline AH & $0,77^{\mathrm{a}} \pm 0,09$ \\
AM & $0,32^{\mathrm{b}} \pm 0,03$ \\
LC & $>0,25$ \\
LPP & $>3,18$ \\
\hline
\end{tabular}

Letras diferentes en la columna $\mathrm{IC}_{50}(\mathrm{mg} / \mathrm{ml})$ implican diferencias significativas $(\mathrm{p}<0,05)$.

Tabla 1. Inhibición de la proliferación celular. $\mathrm{IC}_{50}$ : concentración de proteína que inhibe el $50 \%$ de la proliferación celular.
B. Aislado Amaranthus hypochondriacus

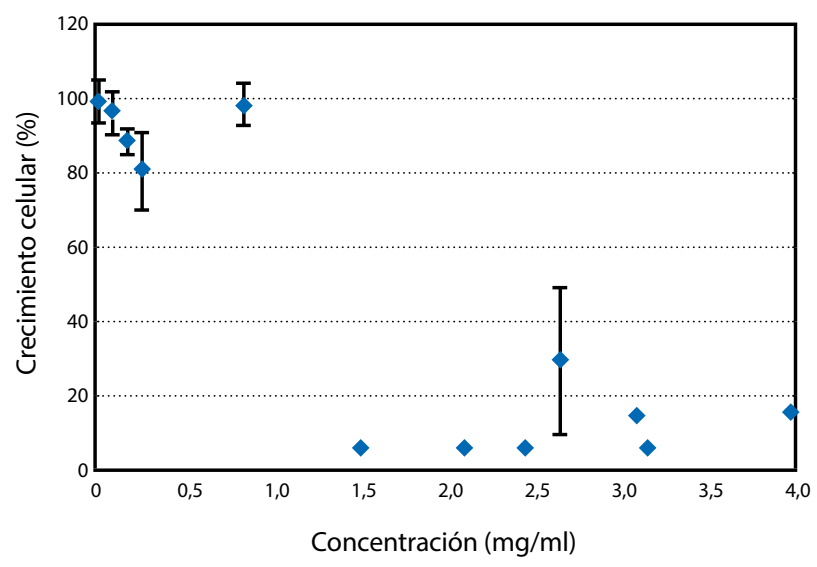

D. LPP

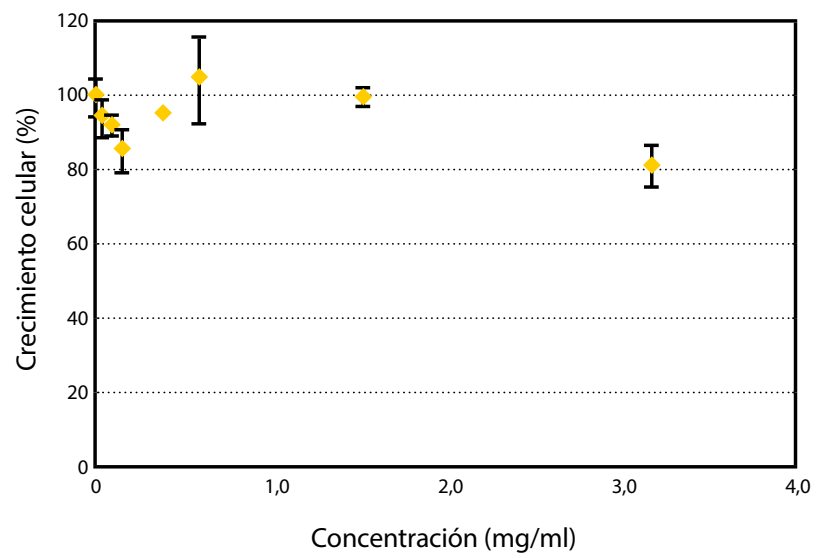

Figura 5. Actividad antiproliferativa. Tinción cristal violeta. A. Aislado de Amaranthus mantegazzianus. B. Aislado Amaranthus hypochondriacus. C. Lectina comercial. D. Lectina parcialmente purificada (LPP). 


\section{Conclusiones}

De acuerdo a los objetivos propuestos, en este trabajo se logró purificar y caracterizar la lectina de Amaranthus hypochondriacus. Durante la caracterización de la muestra se determinó que la lectina es un dímero con peso molecular de aproximadamente $67 \mathrm{kDa}$ (cada subunidad tiene una masa aproximada de $35 \mathrm{kDa}$ ) que se encuentra unido por interacciones no covalentes. El resultado obtenido es equivalente a lo informado en la bibliografía para la fracción lectina purificada a partir de otras especies de este cultivo (Koeppe y Rupnow, 1988; Zenteno y Ochoa, 1988; Singh, et al., 1993; Singh, et al., 1994; Rinderle, et al., 1989; Rinderle, et al., 1990). El proceso de purificación realizado fue eficaz, ya que se pudo eliminar proteínas interferentes presentes en la muestra original (extracto crudo) manteniendo la actividad hemaglutinante. Sin embargo, comparando la actividad antiproliferativa del aislado de Amaranthus hypochondriacus con la de LPP, es posible observar que el protocolo de purificación utilizado conlleva a una pérdida de esta actividad. Esto podría deberse a la pérdida de algún compuesto que actúe sinérgicamente con la lectina en la actividad antiproliferativa.

Los resultados obtenidos para el aislado de Amaranthus mantegazzianus, con el que se logra obtener efectos sobre las células tumorales a menor concentración que para el aislado de Amaranthus hypochondriacus, sugieren profundizar en la investigación sobre cuál es el mecanismo de acción de la lectina proveniente de esta especie. Aunque existen en bibliografía datos que dan cuenta de la resistencia de algunas lectinas a la hidrólisis gastrointestinal (Wang, et al., 1998; González de Mejía y Prisecaru, 2005) se debe estudiar específicamente la resistencia de lectina de amaranto antes de aplicarla en la formulación de un ingrediente funcional.

\section{Reconocimientos}

Este trabajo fue realizado gracias al financiamiento recibido por parte de UNLP, CONICET y el Ministerio de Ciencia, Tecnología e Innovación Productiva mediante los proyectos: 11/X624 "Proteínas y lectinas de amaranto con potencial acción protectora sobre los sistemas cardiovascular y gastrointestinal", PIP 1109 "Proteínas y lectinas de amaranto con potencial acción protectora sobre los sistemas cardiovascular y gastrointestinal" y PICT 0937 "Péptidos vegetales con actividad antihipertensiva, inmunomodulatoria y antiproliferativa. Acción biológica in vivo, mecanismos de acción y evaluación de su aplicación en alimentos funcionales".

\section{Referencias}

Barrio, D.A., y Añón, M.C., 2010. Potential antitumour properties if a protein isolate obtained from the seeds of Amaranthus mantegazzianus. En: European Journal of Nutrition, 49(2), pp.73-82.

Bhutia, S.K., y Maiti, T.K., 2008. Targeting tumors with peptides from natural sources. En: Trends in Biotechnology, 26(4), pp.210-217.

Caselato-Sousa, V.M. y Amaya-Farfán, J., 2012. State of knowledge on amaranth grain: a comprehensive review. En: Journal of Food Science, 77(4), pp.R93-R104.

Fritz, M., Vecchi, B., Rinaldi, G. y Añón, M.C., 2011.
Amaranth seed protein hydrolysates have in vivo and in vitro antihypertensive activity. En: Food Chemistry, 126(3), pp.878-884.

García Fillería, S.F. y Tironi, V.A., 2015. Application of amaranth protein isolate and hydrolysate on a reduced salt fish restructured product: Antioxidant properties, textural and microbiological effects. En: International Journal of Food Science and Technology, 50(6), pp.1452-1460.

González de Mejía, E. y Dia, V.P., 2010. The role of nutraceutical proteins and peptides in apoptosis, angiogenesis, and metastasis of cancer cells. En: Cancer Metastasis Reviews, 29, pp.511-528.

González de Mejía, E. y Prisecaru, V.I., 2005. Lectins as bioactive plant proteins: a potential in cancer treatment. En: Critical Reviews in Food Science and Nutrition, 45(6), pp.425-445.

Hernández-Ledesma, B., Hsieh, C.C., y de Lumen, B.O., 2009. Lunasin, a novel seed peptide for cancer prevention. En: Peptides, 30(2), pp.426-430

Instituto Nacional del Cáncer, Ministerio de Salud, Presidencia de la Nación, 2012 Estadísticas: análisis de la situación del cáncer en Argentina. [En línea]. Buenos Aires: INC. [Consulta: 1 de Agosto de 2015]. Disponible en: http:// www.msal.gov.ar/inc/index.php/acerca-del-cancer/ estadisticas.

International Agency for Research on Cancer, World Health Organization, Globocan, 2012. Estimated Cancer Incidence Mortality and Prevalence Worldwide. [En línea]. Francia: IARC. [Consulta: 1 de agosto de 2015]. Disponible en: http://globocan.iarc.fr/Default.aspx.

Kaur, N., Dhuna, V., Kamboj, S.S., Agrewala, J.N. y Singh. J., 2006. Lunasin, a novel antiproliferative and antifungal lectin from Amaranthus viridis Linn seeds. En: Protein and Peptide Letters, 13(9), pp.897-905.

Kobayashi, H., 2013. Prevention of cancer and inflammation by soybean protease inhibitors. En: Frontiers in Bioscience Elite, 5E(3), pp.966-973.

Koeppe, S.J., y Rupnow, J.H., 1988. Purification and characterization of a lectin from the seeds of amaranth (Amaranthus cruentus). En: Journal of Food Science, 53, pp.1412- 1417.

Lam, S.K., y Ng, T.B., 2011. Lectins: production and practical applications. En: Applied Microbiology and Biotechnology, 89(1), pp.45-55.

Laemmli, U. K., 1970. Cleavage of structural proteins during the assembly of the head of bacteriophage T4. En: Nature, 227(5259), pp.680-685

Lipkin, A., Anisimova, V., Nikonorova, A., Babakov, A., Krause, E. y Bienert. M., 2005. An antimicrobial peptide Ar-AMP from amaranth (Amaranthus retroflexus L.) seeds. En: Phytochemistry, 66(20), pp.2426-2431.

Liu, B., Bian, H.J. y Bao, J.K., 2010. Plant lectins: potential antineoplastic drugs from bench to clinic. En: Cancer Letters, 287(1), pp.1-12.

Martínez, E.N. y Añón, M.C., 1996. Composition and structural characterization of amaranth protein isolates. An electrophoretic and calorimetric study. En: Journal of Agricultural and Food Chemistry, 44, pp.2523-2530.

Okajima, T., Nakamura, K., Zhang, H., Ling, N., Tanabe, T. y Yasuda, T., 1992. Sensitive colorimetric bioassays for insulin-like growth factor (IGF) stimulation of cell proliferation and glucose consumption: use in studies of IGF analogs. En: Endocrinology, 4, pp.2201-2212. 
Orsini Delgado, M.C., Galleano, M., Añón, M.C. y Tironi, V.A., 2015. Amaranth peptides from simulated gastrointestinal digestion: antioxidant activity against reactive species. En: Plant Foods for Human Nutrition, 70, pp.27-34.

Orsini Delgado, M.C., Tironi, V.A., y Añón, M.C., 2011. Antioxidant activity of amaranth protein or their hydrolysates under simulated gastrointestinal digestion. En: LWT-Food Science and Technology, 44(8), pp.1752-1760.

Quiroga, A.V., Aphalo, P., Ventureira, J.L., Martínez, E.N., y Añón, M.C., 2012. Physicochemical, functional and angiotensin converting enzyme inhibitory properties of Amaranth (Amaranthus hypochondriacus) 7S globulin. En: Journal of the Science of Food and Agriculture, 92(2), pp.397-403.

Quiroga, A.V., Barrio, D.A., y Añón, M.C., 2015. Amaranth lectin presents potential antitumour properties. En: $L W T$ Food Science and Technology, 60, pp.478-485.

Rastogi, A. y Shukla, S., 2013. Amaranth: a new millenium crop of nutraceutical values. En: Critical Reviews in Food Science and Nutrition, 53(2), pp.109-125.

Rinderle, S.J., Goldstein, I.J., Mattag, K.L. y Ratcliffe, R.M., 1989. Isolation and characterization of amaranthin, a lectin present in the seeds of Amaranthus caudatus, that Recognizes the T- (or Cryptic T)-Antigen. En: The Journal of Biological Chemistry, 264(27), pp.16123-16131.

Rinderle, S.J., Goldstein, I.J. y Remsed, E.E., 1990. Physicochemical Properties of Amaranthin, the Lectin from Amaranthus caudatus seeds. En: Biochemistry, 29, pp.10555-10561.

Sabbione, A.C., Scilingo, A.A. y Añón, M.C., 2015. Potential antithrombotic activity detected in Amaranth proteins and its hydrolysates. En: LWT-Food Science and Technology, 60(1), pp.171-177.

Silva-Sánchez, C., Barba de la Rosa, A.P., León-Galván, M.F., De Lumen, B.O., De LeónRodríguez, A. y González de Mejía, E., 2008. Bioactive peptides in Amaranth (Amaranthus hypochondriacus) seed. En: Journal of Agricultural and Food Chemistry, 56, pp.1233-1240.

Singh, J., Kamboj, K.K., Kamboj, S.S., Sandhu, R.S. y Shangary, S., 1993. Affinity purification and characterization of lectins from two Amaranthus species. En: Plant Science, 94, pp.47-53.

Singh, J., Kamboj, K.K., Kamboj, S.S., Shangary, S. y Sandhu, R.S., 1994. Amaranthus hypochondriacus and A. tricolor lectins: Isolation and characterization. En: Italian Journal of Biochemistry, 43(5), pp.207-218.

Tironi, V.A. y Añón, M.C., 2014. Antioxidant activity of amaranth protein hydrolysate against thermal oxidation of vegetable oils. En: Journal of the American Oil Chemists' Society, 91(9), pp.1583-1594.

Transue, T.R., Smith, A.K., Mo, H., Goldstein, I.J. y Saper, M.A., 1997. Structure of benzyl Tantigen disaccharide bound to Amaranthus caudatus agglutinin. En: Nature structural biology, 4(10), pp.779-783.

Wang, Q., Yu, L.G., Campbell, B.J., Milton, J.D. y Rhodes, J.M., 1998. Identification of intact peanut lectin in peripheral venous blood. En: Lancet, 352(9143), pp.1831-1832.

World Cancer Research Fund International. American Institute for Cancer Research, 2007. Food, nutrition, physical activity, and the prevention of cancer: a global perspective. Washington DC: AICR.

Yu, L.G., Milton, J.D., Fernig, D.G. y Rhodes, J.M., 2001. Opposite effects on human colon cancer cell proliferation of two dietary Thomse-Friedenreich antigen-binding lectins. En: Journal of Cellular Physiology, 186(2), pp.282-287.

Zenteno, E. y Ochoa, J.L., 1988. Purification of a lectin from Amaranthus leucocarpus by affinity chromatography. En: Phytochemistry, 27, pp.313-317. Barrio, D.A., y Añón, M.C., 2010. Potential antitumour properties if a protein isolate obtained from the seeds of Amaranthus mantegazzianus. En: European Journal of Nutrition, 49(2), pp.73-82. 